\title{
The relationship between cortical network structure and the corresponding state space dynamics
}

\author{
Nicole Voges ${ }^{1,2^{*}}$, Laurent Perrinet ${ }^{1}$ \\ From Twentieth Annual Computational Neuroscience Meeting: CNS*2011 \\ Stockholm, Sweden. 23-28 July 2011
}

Most studies on the dynamics of recurrent cortical networks are either based on purely random wiring or neighborhood couplings [1-3]. Neuronal wiring in the cortex, however, shows a complex spatial pattern composed of local and long-range patchy connections, i.e., spatially clustered synapses $[4,5]$.

We ask to what extent such geometric traits influence the 'idle' dynamics of cortical network models. Assuming an enlarged spatial scale we consider distinct network architectures, ranging from purely random or purely locally coupled neurons to distance dependent connectivities that also include patchy projections. Approximately 50000 neurons are spatially embedded in a $2 \mathrm{D}$ sheet of cortex with a side length of five millimeters in order to account for remotely established synapses. Neurons are implemented as conductance based integrate-and-fire neurons with distance-dependent synaptic delays. Network dynamics are simulated with NEST/PyNN [6].

Analyzing the characteristic measures describing spiking neuronal networks (e.g. the correlation coefficient or the coefficient of variation), we explore and compare the phase spaces and activity patterns of our simulation results. As expected from random networks, different dynamical states (e.g. synchronous regular 'SR' or asynchronous irregular 'AI' firing) occur in dependence of the input rate and the relation between exc. and inh. synaptic strengths [1-3]. Non-random networks, however, exhibit higher firing rates, sharper transitions, as well as various types of complex network activities. For example, the amount of local connections clearly influences the boundaries at which the network switches

\footnotetext{
*Correspondence: nicole.voges@uniklinik-freiburg.de

'INCM, UMR6193 CNRS, Aix-Marseille Université, Marseille, France

Full list of author information is available at the end of the article
}

from high (SR) to low (AI) activity. Distance-dependent connectivity structures induce 'new' raster plots, e.g., oblique stripes or spiral structures representing planar and spherical wave propagation. To better describe such activity patterns we computed a delay-dependent correlation coefficient. Such spike patterns indicate a spatiotemporal spread of activity that random networks cannot account for. Furthermore, to determine stability and signal propagation properties, we applied spatially restricted activity injections. Depending on the network architecture, the dynamics may change from AI to SR or wave-like activity, and then switch back or not.

We conclude that (the amount of) local distancedependent connections is an important structural feature of cortical networks since it induces rather complex activity patterns compared to random connectivities. However, we found no clear differences in the dynamics of networks with randomly distributed compared to spatially clustered long-range projections. Further analysis is needed to explore the functional aspects of patchy projection patterns.

\section{Acknowledgments}

This work was supported by EU Grant 15879 (FACETS).

\section{Author details}

${ }^{1}$ INCM, UMR6193 CNRS, Aix-Marseille Université, Marseille, France. ${ }^{2}$ Current address: Funktionelle Sehforschung/Elektrophysiologie, Universitäts-

Augenklinik, Freiburg, Germany.

Published: 18 July 2011

\section{References}

1. Brunel N: Dynamics of sparsely connected networks of excitatory and inhibitory spiking neurons. J. Comput. Neurosci 2000, 8(3):183-208.

2. Kumar A, Schrader S, Aertsen A, Rotter S: The high conductance state of cortical networks. Neural Computation 2008, 20:1-43.

\section{(Ciomed Central}

(c) 2011 Voges and Perrinet; licensee BioMed Central Ltd. This is an open access article distributed under the terms of the Creative Commons Attribution License (http://creativecommons.org/licenses/by/2.0), which permits unrestricted use, distribution, and reproduction in any medium, provided the original work is properly cited. 
3. Voges N, Perrinet L: Phase space analysis of networks based on biologically realistic parameters. J Phys Paris 2009, 104:51-60

4. Binzegger T, Douglas RJ, Martin KAC: Stereotypical bouton clustering of individual neurons in cat primary visual cortex. J. of Neurosci 2007. 27(45):12242-12254.

5. Voges N, Schüz A, Aertsen A, Rotter S: A modeler's view on the spatial structure of intrinsic horizontal connectivity in the neocortex. Prog Neurobiol 2010, 92(3):277-292.

6. Gewaltig MO, Diesmann M: Nest. Scholarpedia 2(4):1430.

doi:10.1186/1471-2202-12-S1-P345

Cite this article as: Voges and Perrinet: The relationship between

cortical network structure and the corresponding state space dynamics. BMC Neuroscience 2011 12(Suppl 1):P345.

Submit your next manuscript to BioMed Central and take full advantage of:

- Convenient online submission

- Thorough peer review

- No space constraints or color figure charges

- Immediate publication on acceptance

- Inclusion in PubMed, CAS, Scopus and Google Scholar

- Research which is freely available for redistribution

Submit your manuscript at www.biomedcentral.com/submit 